\title{
Separation of Stormflow Hydrographs in Surface and Subsurface Flow by Perceptual Based Modelling of Channel Inflow Components
}

\author{
Margret Johst ${ }^{1}$, Markus C. Casper ${ }^{2, *}$, Christoph Müller ${ }^{3}$ and Raimund Schneider ${ }^{4}$ \\ ${ }^{1}$ Department of Civil Engineering, University of Applied Sciences, D-78462 Konstanz, Germany \\ ${ }^{2}$ Department of Physical Geography, University of Trier, D-54286 Trier, Germany \\ ${ }^{3}$ Department of Geography, University of Koblenz-Landau, D-56070 Koblenz, Germany \\ ${ }^{4}$ Department of Soil Science, University of Trier, D-54286 Trier, Germany
}

\begin{abstract}
The aim of this case study was to determine the origin of stormflow runoff in a 31 ha headwater basin in Western Germany. Therefore, the contribution of infiltration excess and saturation overland flow as well as matrix and preferential flow has been assessed along a deeply incised channel of $300 \mathrm{~m}$ length. Measurable parameters and simple algorithms were used to assess the flow rate of the different runoff components. Only the scaling parameter $c f$ that represents converging flow processes and controls the actual height of the saturated zone along the channel incision has been calibrated. The results showed that during wet conditions the subsurface flow rates exceed the surface flow rates tremendously. In contrast, for the short but intense summer storm the hydrograph consists solely of surface runoff components. Obviously, the parameter $c f$ accounts for the pre-event condition of the catchment. This leads to the conclusion, that the extension of the contributing subsurface space mainly governs stormflow processes. Further investigations shall focus on the relationship between subsurface flow processes and the lateral and vertical extension of the saturated zone.
\end{abstract}

Keywords: hillslope hydrology, low mountain ranges, peak flow, preferential flow, subsurface flow, stormflow, rainfallrunoff-modelling, runoff generation.

\section{INTRODUCTION}

Depending on their background and experiences, decision-makers in forestry, agriculture, landscape management, water resources and engineering hydrology have different and sometimes contradictory perceptions of stormflow generation processes and the source areas of peak flow. The implementation and effectiveness of flood mitigation measures, however, is critically dependent on the underlying process perception.

For decades, it is well known among field hydrologists that stormflow in forested low mountain range landscapes consists mainly of fast subsurface flow as reviewed by $[1,2]$. In the $1980^{\text {th }}$ [3-5] have observed the very fast bypassing flow in preferential pathways. Tracer studies (e.g. [6-11]) provided evidence of a displacement of so-called old water. Later on [12-15] proved the strong impact of the basin geomorphology and the antecedent moisture condition on the runoff response.

On agricultural land, infiltration excess overland flow may result from crusting, compaction or hydrophobicity of the soil surface. Sprinkling experiments are often performed to investigate correlations between soil properties and runoff

*Address correspondence to this author at the Department of Physical Geography, University of Trier, Campus II, D-54286 Trier,

Tel: 0049-651-2013976; Fax: 0049-651-2014518;

Email: casper@uni-trier.de processes (e.g. [16-18]). Infiltration excess overland flow may occur also on pastureland due to compaction of the upper soil, a dense litter cover or saturation of the soil. In wide flood plains or at converging slopes with a concave longitudinal profile saturated areas may extent during long lasting rainfall (e.g. [19]), known as the "variable area concept"([20]).

In contrast to the source areas of surface flow that might be identified and delineated in the field, the subsurface flow processes are more difficult to capture (e.g. [21-23]). In addition, it is even more complicate to simulate these processes by applying rainfall-runoff models (e.g. [24]). Especially if quantitative values of mean subsurface flow rates during storms are claimed, research is still at the beginning. Reasons for this lack of knowledge are the general rareness of observations during higher flood events, the nonlinearity of subsurface processes (e.g. [25]), the heterogeneity of the plots under investigation (e. g. [16] and [26]), and the difficulties of scaling up the processes measured at the plot or hillslope scale.

In our study area, which is used for both agriculture and forestry, the contribution of overland flow to floods is a highly controversial issue. Therefore, our aim was to quantify the flow rates of different runoff components during single floods. Here, we focus on a channel section of $300 \mathrm{~m}$ and use a model approach with only one calibration parameter that is comprehensible for decision-makers in practice. This case study shall help to describe the contribution of fast flow components and consequently the effect of flood reten- 


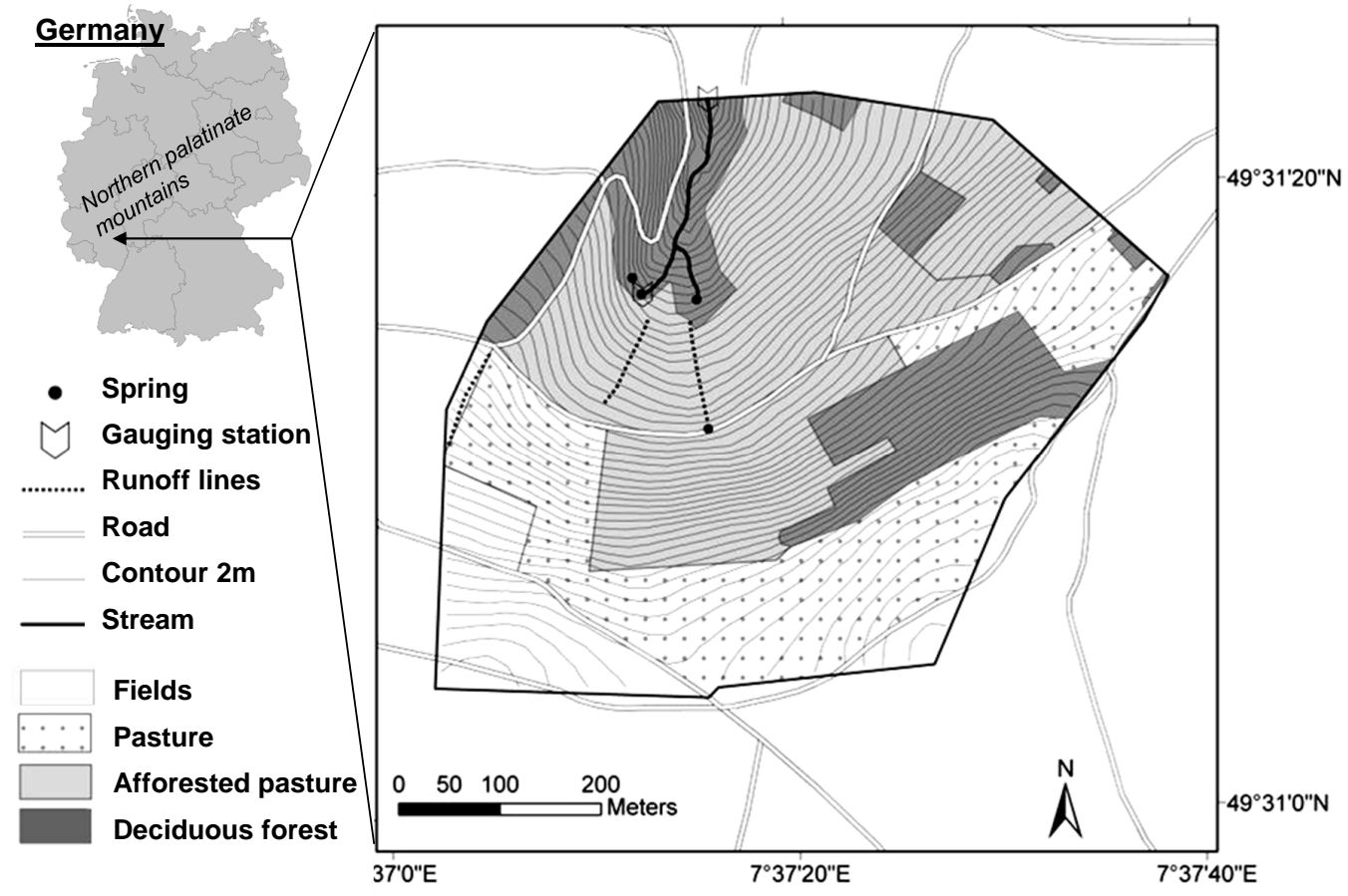

Fig. (1). Testside "Frankelbach" in the northern palatinate mountains: Discharge gauging stations, springs, runoff concentrating features ("runoff lines") and landuse.

tion measures more quantitatively. The assumptions and parameters are based on the results of numerous field experiments.

In hydrology research, there is a lack of models that on the one hand simulate single runoff generation processes and on the other hand have a limited number of calibration parameters. Due to the above explained complexity of flow processes and in order to simulate the whole water cycle the common simulation models often comprise dozens of calibration parameters. The number of parameter increases tremendously if the model is additionally spatially distributed. A great deal of calibration parameters means that firstly the simulation of the processes is less transparent, secondly the calibration of the model is time-consuming and thirdly an intercorrelation of the calibration parameters can not be excluded. In our event-based model we tried to use only one or two calibration parameters by neglecting processes of minor importance and by disregarding partly the principle of mass conservation.

\section{STUDY SITE}

In the low mountain range basin Frankelbach (RhinelandPalatinate, Germany) hydrological observations have been carried out between 2004 and 2009 aiming to investigate stormflow generation and erosion processes, as well as to assess the performance of flood retention measures ([18] and [27]). The subbasin presented in this article (Fig. 1) is a hollow with a mean slope of $11^{\circ}$. The area is 31 ha, the elevation 330 to $453 \mathrm{~m}$ AMSL and annual precipitation averages $700 \mathrm{~mm}$.

Permian sand- and siltstones with interlaminated clayey layers ("Rotliegendes") built up the geological basement. The hillslopes are mainly covered by two layers downhill dislocated by solifluidal processes under past periglacial conditions. The underlying layer ("basal layer", weathered rock, sandy loam) is generally dense and less permeable for water while the overlaying substrate of about $40 \mathrm{~cm}$ depth ("main layer", mixture of eolian sediments and weathered rock, silty loam) is porous with medium to high hydraulic conductivity. Hence, the outcomes of this are stagnosols on moderate slopes. Cambisols are common on steep slopes while colluvisols (anthrosols) are located in depressions, plain sites and in the thalwegs. The soil depth above the "base layer" varies between $40 \mathrm{~cm}$ and $2 \mathrm{~m}$.

Most of the basin area is used as pastureland but has been afforested recently to mitigate fast surface runoff generation. The channel with a mean slope of $9^{\circ}$ is deeply incised into the sedimentary material and is surrounded by old deciduous forest. The springs in this region are evidence of an aquiclude and lie about $3 \mathrm{~m}$ below the upper edge of the respective gully headcut. They either are pipes of 10 to $30 \mathrm{~cm} \mathrm{di-}$ ameter or diffuse seeping areas. During wet conditions the pipe springs react very fast on higher precipitation as shown in Fig. (6). The strong headward erosion especially at the pipe springs indicate strong subsurface flow processes at these points.

Due to the deeply incised V-shaped channels and to the rather high slope gradient permanently saturated areas are rare in this region. Emergence of higher groundwater level is evident in the thalwegs at the lower part of the hollow as seen at the vegetation pattern (dotted lines in Fig. 1). Around these so-called runoff lines saturation overland flow might occur but since gullies or rills are not visible at the channels headcut this is likely not a dominant process.

Discharge has been captured in 10-minutes timesteps at two V-notch weirs, one at a large pipe spring and the other 


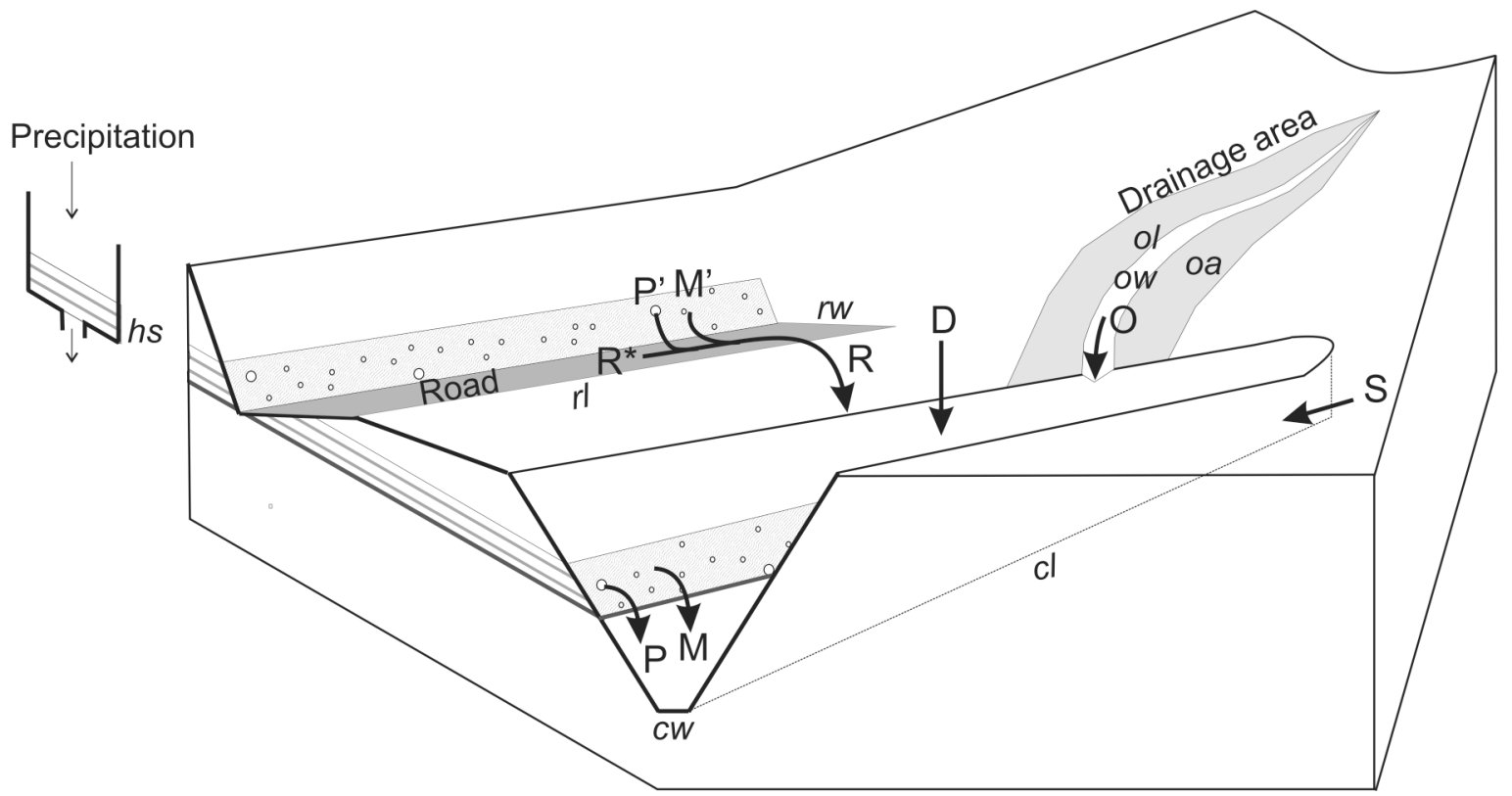

Fig. (2). Definition sketch of the channel reach (cw: channel width, cl: channel length), the slope incising roads (rw: road width, rl: road length), the drainage area $(o a)$ and runoff lines for saturated overland flow (ow: width of runoff lines, ol: length of runoff lines) and the storage to calculate the height of the saturated zone $(h s)$. Further abbreviations are defined in Eq. 1.

about $300 \mathrm{~m}$ downstream. The precipitation is collected with a tipping bucket about $2 \mathrm{~km}$ away from the test site. Between 2004 and 2009 no extreme precipitation occurred. During this period highest stormflow is shown in this article. Furthermore, several extensive measurement campaigns have been carried out yielding information on the infiltration capacity, the hydraulic conductivity and flow processes at different sites [18].

\section{MATERIAL AND METHODS}

\subsection{Model Approach}

To assess the contribution of different flow components, we confine ourselves solely to the inflow into the channel. That means we consider only the channel reach between two gauging stations and attempt to balance the input of the different runoff components along this reach (Fig. 2). Here, the channel edge and the channel headcut can be seen as system boundaries. To quantify the surface runoff the contributing basin area is taken into account, whereas for the subsurface flow components the permeability of the channel edge is considered.

We use precipitation as driving variable but do not claim to fulfil the principle of mass conservation. In considering only the channel section and single floods the parameters precipitation, evaporation, storage and runoff can hardly be balanced: Precipitation that falls some $100 \mathrm{~m}$ away from the channel edge, for instance at the watershed, does not necessarily contribute to the peak flow since the subsurface matrix flow is not fast enough (mean hydraulic conductivity $=400$ $\mathrm{cm} \mathrm{d}^{-1}$ ). Instead, converging old groundwater near the channel may strongly contribute to the peak flow. Interception and evaporation are not simulated, since these processes reduce the peak flow only very slightly.

The model algorithms are written in the free $\mathrm{R}$ programming language. As input data only time series of precipitation and discharge are needed. Furthermore, basin-specific constant parameters have to be defined (see chapter "Model parameters"). Before applying the model to a certain flood event, the lag time between the maximum precipitation and the peak discharge has to be assessed. In our event-based model only one calibration parameter (parameter $c f$ ) is used, that is calibrated by visually comparing the simulated and the measured hydrograph. This calibration parameter implies the effect of antecedent soil moisture. Thus, the determination of initial conditions is part of the calibration process and model initialisation and equilibration are not necessary.

\subsection{Definition of Stormflow Components}

The discharge at the lower gauging station $Q$ is the sum of eight flow components as shown in Eq.1. The calculation of the subsurface inflow of springs (component $S$ ) is based on runoff measurements at one spring near the channel headcut. For the roads near the channel we assume that the infiltration excess overland flow (component $R$ ) as well as the water seeping through the road batter (components $M^{\prime}$ and $\left.P^{\prime}\right)$ flows directly into the channel.

Since the precipitation is captured in 10 minutes-timesteps, calculations have been carried out in 10 minutes-timesteps. Finally, the different runoff components are given in 1/s.

$$
Q(t)=D(t)+S(t)+R(t)+O(t)+M(t)+M^{\prime}(t)+P(t)+P^{\prime}(t)
$$

with $D$ precipitation directly falling onto the channel

$S$ subsurface inflow of springs

$R$ infiltration excess overland flow from roads

$O$ saturation overland flow

$M$ matrix flow along the channel batter

$M$ ' matrix flow along the road batter

$P$ pipe flow along the channel batter

$P^{\prime}$ pipe flow along the road batter 


\subsection{Calculation of Single Stormflow Components and Parameters}

The component $D$ (precipitation directly falling onto the channel) is calculated depending on the precipitation Prec [mm/10min], the channel length $c l[\mathrm{~m}]$ and channel width $c w$ [m] (Eq. 2).

$$
D(t)=\operatorname{Prec}(t) \cdot c w \cdot c l
$$

To assess $S$ (subsurface inflow of springs) the measured runoff at one pipe spring $s q[1 / \mathrm{s}]$ has been multiplied with the number of all springs sno [-] as estimated from field surveys during wet condition (Eq. 3).

$s(t)=s q(t) \cdot s n o$

$R$ (infiltration excess overland flow from roads) has been calculated using a constant road runoff coefficient $\operatorname{rrc}[-]$. The road area is defined by their width $r w[\mathrm{~m}]$ and their length $r l[\mathrm{~m}]$ (Eq.4). Only those road sections are considered that lead the runoff to areas close to the channel. Additionally, since these roads are partly incising the slope, both matrix flow $M^{\prime}$ and pipe flow $P^{\prime}$ along the road batters has been assessed, too, as described in Eq.7b and 8b.

$R(t)=\operatorname{Prec}(t) \cdot r w \cdot r l \cdot r r c$

Generally, overland flow runs off as sheet flow if the volume is small but concentrates in rills if the flow volume increases and the slope converge downwards. Consequently, the existence of rills or even gullies indicates fast flow processes on the surface ([28]). Larger rills or gullies could not be found in our catchment. However, as seen in Fig. (1) three so-called runoff lines are mapped. These lines are geomorphologic thalwegs, where the groundwater table is rather high due to subsurface flow convergence. Here, hydrophilic plant species are common. In our approach, these runoff lines are seen as constantly saturated areas with a mean width $o w[\mathrm{~m}]$ and a total length $o l[\mathrm{~m}]$. In addition, a more or less expanding area $o a\left[\mathrm{~m}^{2} / \mathrm{m}\right]$ along these runoff lines gets saturated during higher rainfall. Conceptually, a certain percentage $\operatorname{orc}[-]$ of the precipitation that falls on these areas is directly led to the channel as component $O$ (saturation overland flow):

$O(t)=\operatorname{Pr} e c(t) \cdot o l \cdot(o w+o a \cdot o r c)$

The routing of surface flow components $\mathrm{D}, \mathrm{O}$ and $\mathrm{R}$ has not been calculated, that means the water reach the gauging station at the basin's outlet within 10 minutes. This corresponds to a flow velocity of $17 \mathrm{~cm} / \mathrm{s}$ for a distance of $100 \mathrm{~m}$.

To simulate the retention of subsurface flow the linear storage concept is used as sketched in Fig. (2). In our model the parameter $h s[\mathrm{~mm}]$ (Eq. 6) can be defined as height of the saturated zone along the channel incision without convergence flow processes. After a certain lag time $l t[\mathrm{~h}]$ the water level in the storage rises within one timestep $t$ due to precipitation Prec [mm/10min] and decreases due to a constant outflow using a recession coefficient $k$ [1/10min].

$$
h s(t)=h s(t-1)+\operatorname{Pr} e c(t-l t)-h s(t-1) \cdot k
$$

Table 1. Constant Parameters

\begin{tabular}{|l|c|c|}
\hline \multicolumn{1}{|c|}{ Parameter } & Unit & Value \\
\hline \hline Length of channel $c l$ & {$[\mathrm{~m}]$} & 300 \\
Width of channel $c w$ & {$[\mathrm{~m}]$} & 3 \\
\hline Number of springs $s n o$ & {$[\mathrm{~m}]$} & - \\
\hline Length of roads $r l$ & {$[\mathrm{~m}]$} & $300(100)^{{ }^{*} 1}$ \\
Width of roads $r w$ & {$[\mathrm{~m}]$} & 2.5 \\
Runoff coefficient for roads $r r c$ & {$[-]$} & 0.7 \\
\hline Length of runoff lines $o l$ & {$[\mathrm{~m}]$} & 180 \\
Width of runoff lines $o w$ & {$[\mathrm{~m}]$} & 0.5 \\
Drainage area along runoff lines oa & {$\left[\mathrm{m}^{2} / \mathrm{m}\right]$} & 3 \\
Runoff coefficient for drainage area orc & {$[-]$} & 0.7 \\
\hline Hydraulic conductivity $k f$ & {$[\mathrm{~cm} / \mathrm{d}]$} & 400 \\
\hline Number of pipes $p n o$ & {$\left[1 / \mathrm{m}^{2}\right]$} & 20 \\
Mean flow rate of pipes $p q$ & {$[\mathrm{ml} / \mathrm{s}]$} & 7 \\
\hline Recession coefficient of storage $k$ & {$[1 / 10 \mathrm{~min}]$} & 0.008 \\
\hline Lag time $l t$ & {$[\mathrm{~h}]$} & 5 \\
\hline
\end{tabular}

${ }^{*}$ in parentheses: length of roads that are incising slopes (is taken to calculate $\mathrm{M}^{\prime}$ and $\mathrm{P}$ )

where: $h s(t)=0$ for $t \leq l t$

The matrix flow rate $(M)$ as well as the flow rate of pipes $(P)$ depends on the porosity of the soil and the actual hydraulic head. Subsurface flow processes, be it pressure propagation or preferential flow along an impermeable layer, clearly increase if the soil reaches a certain degree of saturation ([5]; [13]; [28]). $M$ (matrix flow) is calculated using $h s$ [dm], twice the channel length $\mathrm{cl}[\mathrm{dm}]$ or road length $\mathrm{rl}[\mathrm{dm}]$ and the saturated hydraulic conductivity $k f[\mathrm{dm} / \mathrm{s}]($ Eq. $7 \mathrm{a})$. Finally, to account for the convergence of the water in the lower part of the hollow $M$ has been multiplied by a socalled convergence factor $c f[-]$ that is the only one parameter that has to be calibrated in this modelling approach.

for channel edge: $M(t)=k f \cdot h s(t) \cdot 2 \cdot c l \cdot c f$

for road batter: $M^{\prime}(t)=k f \cdot h s(t) \cdot r l \cdot c f$

To calculate $P$ (pipe flow) the number of lateral pipes pno $\left[1 / \mathrm{m}^{2}\right]$ along the channel edge as well as a mean flow rate $p q[1 / \mathrm{s}]$ has been assessed (Eq. 8a). Again, the convergence factor $c f[-]$ is used to inversely determine the contributing subsurface flow. In calculating $M^{\prime}$ and $P^{\prime}$ for the road batter the length of the slope incising roads $r l$ has been taken instead of $\mathrm{cl}$ (Eq. $7 \mathrm{~b}$ and 8b).

for channel edge: $P(t)=p n o \cdot p q \cdot h s(t) \cdot 2 \cdot c l \cdot c f$

for road batter: $P^{\prime}(t)=p n o \cdot p q \cdot h s(t) \cdot r l \cdot c f$

\subsection{Model Parameters}

The model parameters (Table 1) are mainly derived from field surveys and field experiments. The runoff coefficients $r r c$ and orc are based on sprinkling experiments (e.g. [18]). 
Table 2. Non-Constant Parameters

\begin{tabular}{|c|c|c|}
\hline Parameter & Unit & Meaning and determination \\
\hline \hline Height of saturated zone $h s$ & {$[\mathrm{~mm}]$} & $\begin{array}{c}\text { Height of saturated zone along the channel batter and the road batter (Fig. 2), calcu- } \\
\text { lated by using the linear storage concept }\end{array}$ \\
\hline Convergence factor $c f$ & {$[-]$} & $\begin{array}{c}\text { Calibrations parameter that comprises various impact factors on subsurface flow (e.g. } \\
\text { hydraulic gradient and convergence of water in the saturated zone) }\end{array}$ \\
\hline
\end{tabular}

Table 3. Characteristics of the Selected Storms

\begin{tabular}{|c|c|c|c|c|c|}
\hline \multirow[b]{2}{*}{ Event type } & \multirow[b]{2}{*}{ Date in 2008} & \multicolumn{2}{|c|}{ Precipitation } & \multicolumn{2}{|c|}{ Discharge } \\
\hline & & $\begin{array}{c}\text { Total Height } \\
{[\mathrm{mm}]}\end{array}$ & $\begin{array}{l}\text { Max. Intensity } \\
\text { [mm/10min] }\end{array}$ & $\begin{array}{c}\text { Max. Specific Discharge } \\
{\left[\mathbf{l} / \mathbf{s} / \mathbf{k m}^{2}\right]}\end{array}$ & $\begin{array}{c}\text { Runoff Coefficient }{ }^{* 1} \\
{[\%]}\end{array}$ \\
\hline \multirow{2}{*}{ Double-peak in winter } & Feb 2 & 23.3 & 0.64 & 59 & 48 \\
\hline & Feb 6 & 19.4 & 2.3 & 109 & 61 \\
\hline Highest peak in spring & Mar 12 & 37.2 & 5.0 & 216 & 57 \\
\hline Thunderstorm & May 30 & 13.5 & 5.6 & 19.3 & 3 \\
\hline
\end{tabular}

${ }^{* 1}$ runoff coefficient is calculated separating a constant base flow from the hydrograph

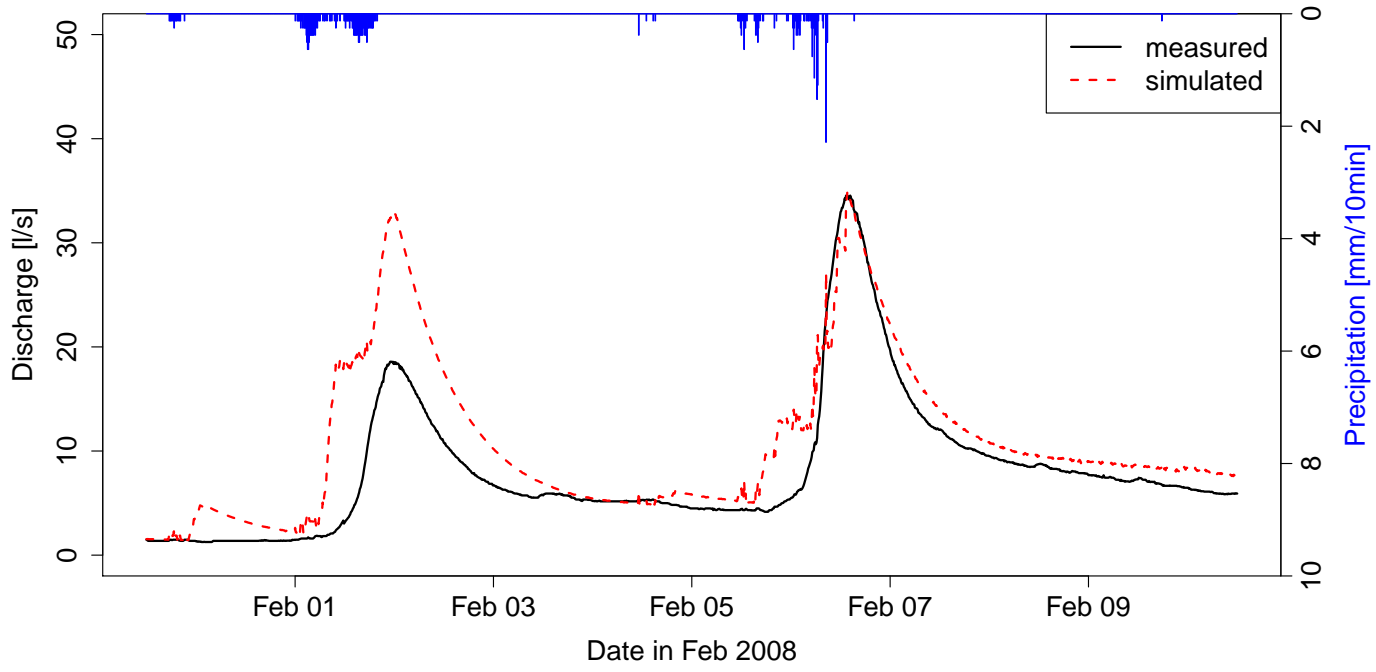

Fig. (3). Model results for the double-peak event $(c f=13)$.

The lag time $l t$ is the time between max. precipitation and peak flow and has been determined for several floods by using measured precipitation and measured runoff. For the higher floods (with subsurface runoff) the lag time was around 5 hours. The recession coefficient $k$ is derived from falling limbs in the runoff hydrograph by trial and error. The parameters of pipes are assessed according to empirical values in the literature. Assuming a pipe diameter between 5 and $0.2 \mathrm{~cm}$ the flow rate $p q$ for a single pipe lies between $5 \bullet 10^{-5}$ and $0.0201 \mathrm{~s}^{-1}$ according to mean flow velocities given by $[5,29]$.

One of the most important parameter in our model approach is the so-called convergence factor $c f$ (Table 2). Convergence is sometimes also called "flow accumulation". At concave shaped slopes, the water converges resulting in a so called saturated wedge at the lower slope and an increase of the hydraulic head at the lowest point. Another effect of this convergence is a higher connectivity of pipes and the drainage of the soil matrix versus pipes respectively (e.g. $[2,21]$ and [30]). The parameter $c f$ can also be seen as representative for the subsurface contributing area, or in other words the subsurface contributing space. Since no piezometers have been installed in the field the actual hydraulic head is not known.

\subsection{Selected Storms}

Three different storm events have been chosen as listed in Table $\mathbf{3}$ and shown in Figs. (3 to 6). The manually selected floods should represent different flood situations and additionally their peak discharge should be as high as possible: The second peak of the double-peak event represents the runoff response during wet moisture state (first event). In spring the runoff coefficients are usually highest as demonstrated for the overall highest flood peak on March 12, 2008 (second event). 


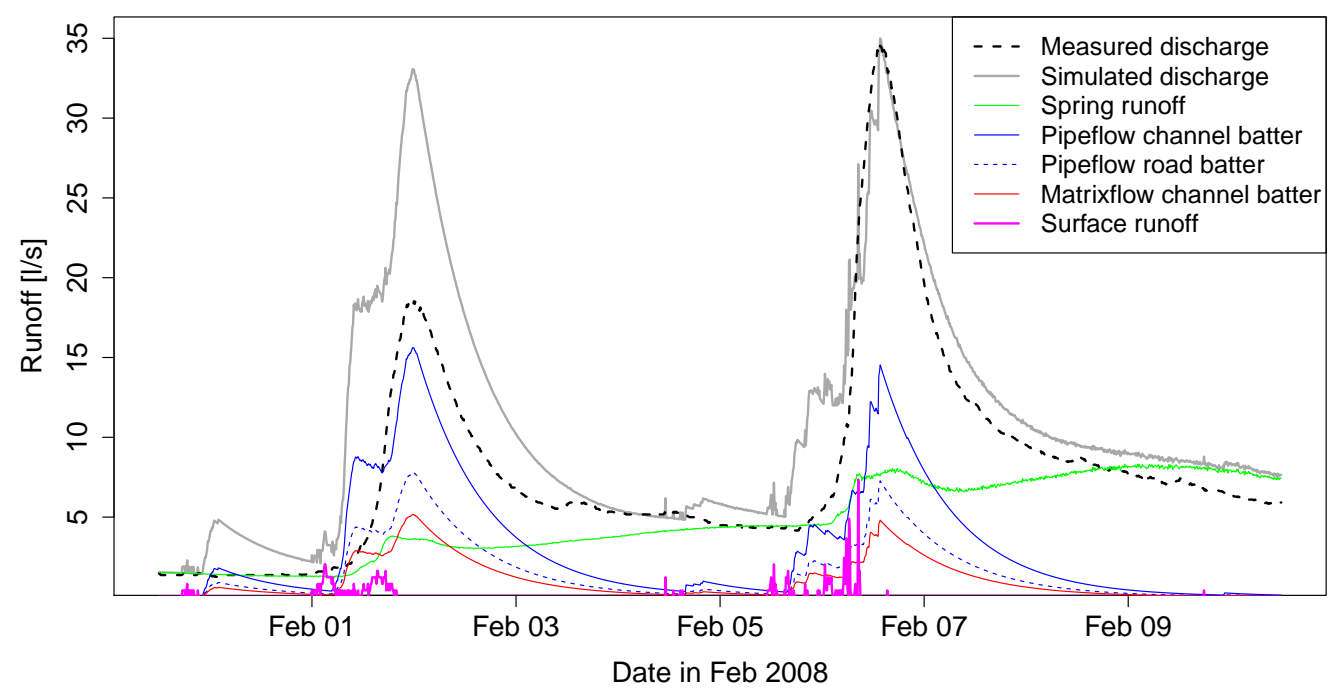

Fig. (4). Hydrographs of the simulated stormflow components for the double-peak event.

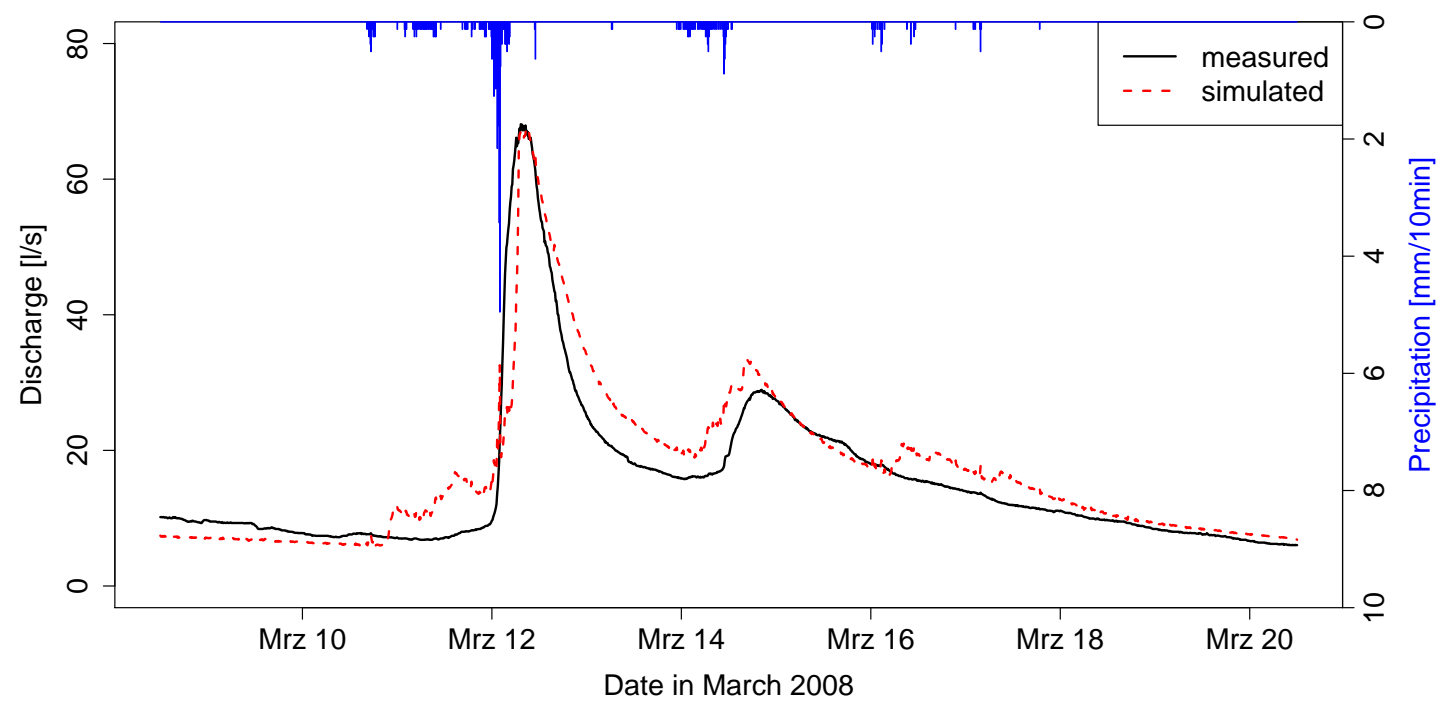

Fig. (5). Model results for the overall highest storm $(c f=13)$.

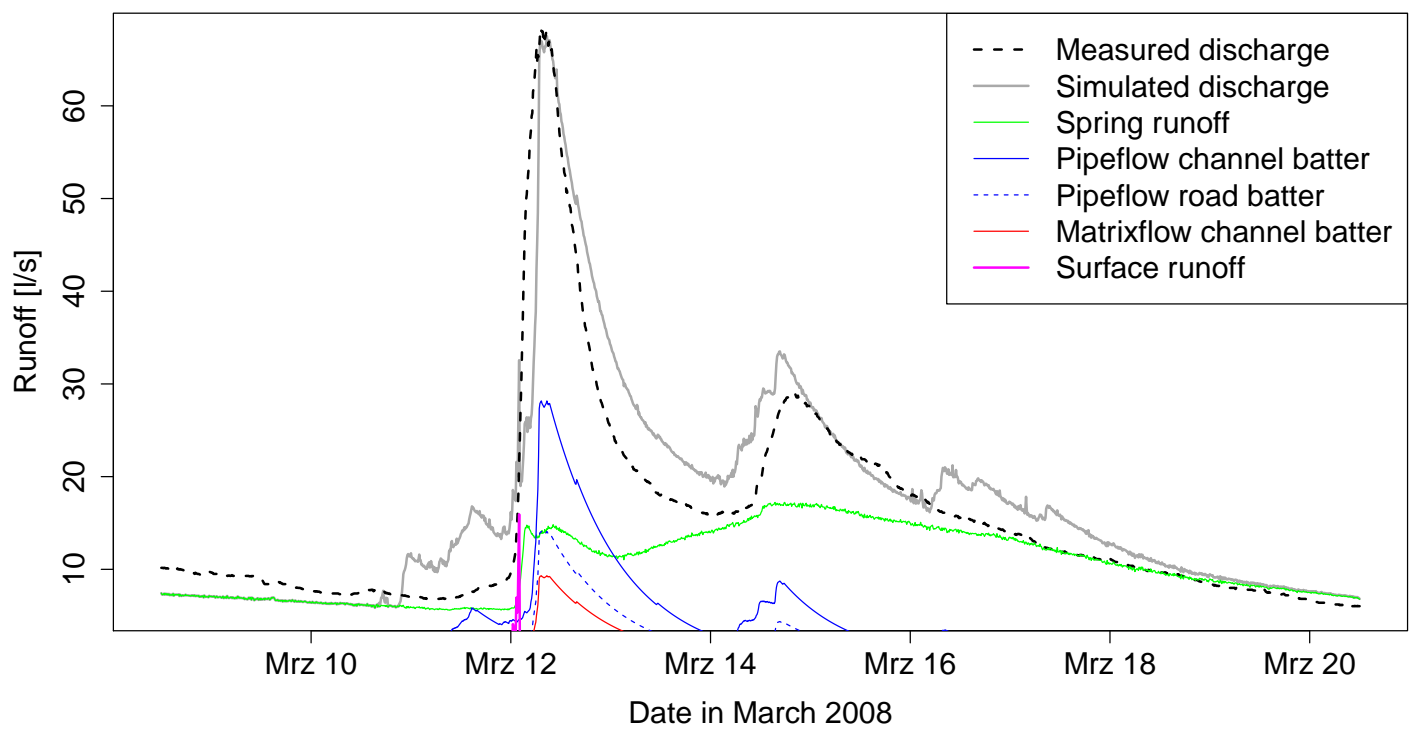

Fig. (6). Hydrographs of the simulated runoff components for the highest peak. 
Table 4. Contribution of Stormflow Components [\%] at the Moment of Peak Flow

\begin{tabular}{|c|c|c|c|c|c|c|c|c|}
\hline Event & D & S & R & O & M & M' & P & P' \\
\hline \hline Double-peak & 0 & 22 & 0 & 0 & 14 & 2 & 41 \\
\hline Highest peak & 0 & 21 & 0 & 0 & 14 & 21 & 42 \\
\hline Summer storm & 47 & 1 & 27 & 24 & 0 & 0 & 0 & 0 \\
\hline
\end{tabular}
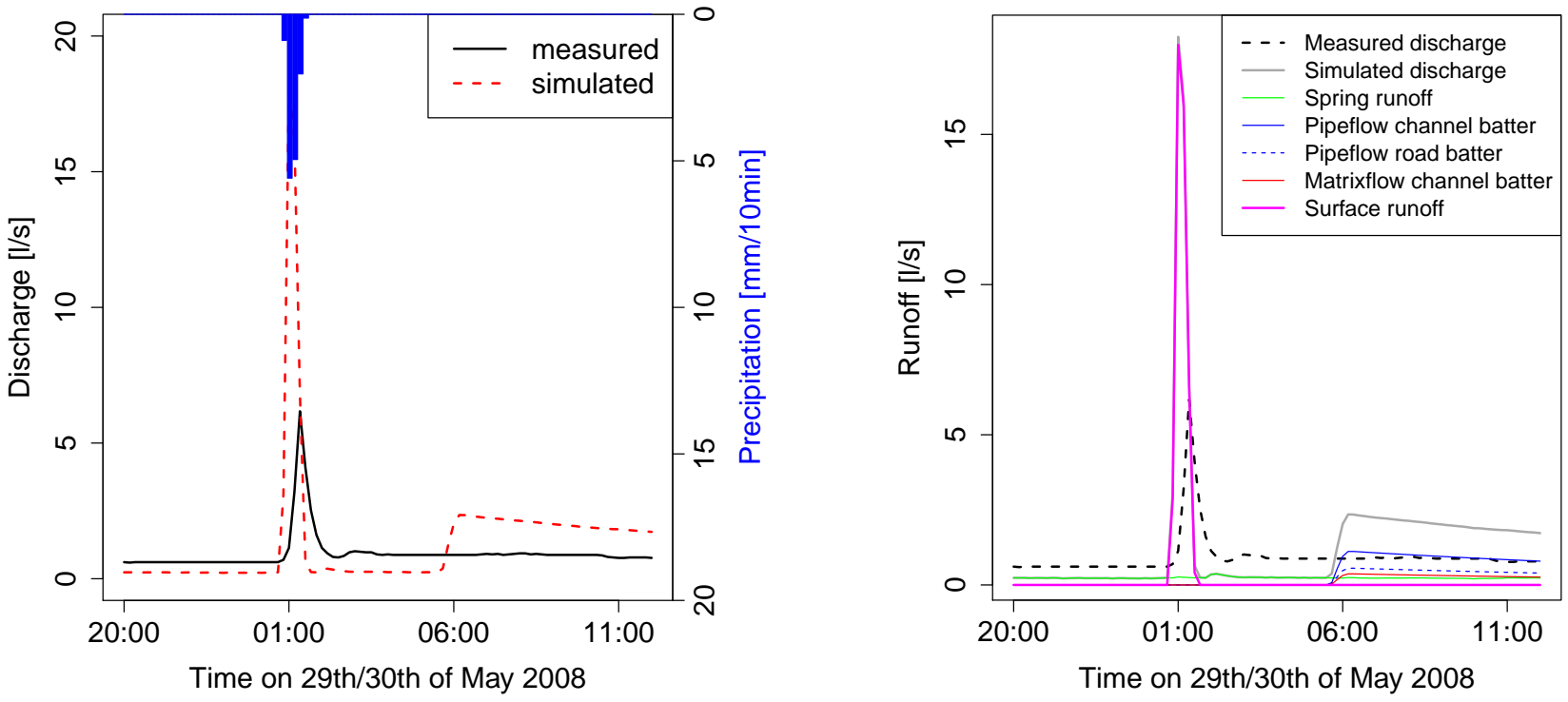

Fig. (7). Model results for the summer storm $(c f=1)$ on the left side and hydrographs of the simulated runoff components on the right side.

event). The last event is a typical response to summer storms of medium magnitude and features a very short lag time as well as a very sharp increasing and falling limb (third event).

\section{RESULTS}

\subsection{Double-Peak Event in Winter}

The second peak of the double-peak event is well simulated if the convergence factor $c f$ is set to 13 (Fig. 3). However, the first peak is strongly overestimated. Here, the initial soil moisture is lower and therefore subsurface flow convergence is not as strong as for the second peak. For the entire double-peak event the maximum of $h s$ (height of the saturated cross section area along the channel edge) multiplied with $c f$ is $18.2 \mathrm{~cm}$.

Even if maximum parameter values for the fast responding areas $(D, O$ and $R)$ are assumed their contribution to the peak flow is still little (Fig. 4 and Table 4). For the second peak, the highest inflow rate of the summed maximized direct flow components is $71 \mathrm{~s}^{-1}$. Here, one has to keep in mind, that this direct runoff is not delayed in the model and reaches the channel within one timestep and is therefore likely higher and faster than in reality.

\subsection{Highest Storm in Spring}

The results for the highest storm (Fig. 5) are similar to the ones of the double peak event. Again, if $c f$ is set to 13 the peak flow could be simulated well. The maximum of $h s$ multiplied with $c f$ is $33 \mathrm{~cm}$.
In Fig. (6) and Table 4 the contribution of the single stormflow components is displayed. As seen in Fig. (6) the percentage of the maximum flow of the very fast responding components $D, O$ and $R$ is approximately $25 \%$ of the peak flow. However, since the measured peak flow occurs first about 5 hours after the highest 30min-precipitation (Fig. 4 , Table 3 ) the components $D, O$ and $R$ do not contribute at all or - in case of a delay - only very little to the peak flow. According to these model results $P$ has the highest portion of the peak flow (Table 4). But, as discussed later the calculation of $M$ and especially $P$ is very uncertain.

\subsection{Storm in Summer}

In contrast to the above showed events, the simulated discharge for the rather low summer storm is much higher than the measured peak flow (Fig. 7). Here, $M$ and $P$ are extremely low and the calculated peak flow consists nearly exclusively of the components $D, O$ and $R$ (Fig. 7 and Table 4).

\section{DISCUSSION}

For both events at wet moisture state featuring runoff coefficients around $60 \%$ the subsurface flow components $S, M$ and $P$ solely govern the peak flow that occurs some hours after the maximum rainfall. Even if the directly contributing components $O$ and $R$ would reach the channel more delayed, their portion of the peak flow would be little. The short but intense summer storm at rather dry moisture state does not trigger subsurface flow. Therefore, the peak flow consists nearly exclusively of the direct components $D, O$ and $R$ and the runoff coefficient is only $3 \%$. 


\subsection{Evaluation of the Model Approach}

The motivation to set up the model was to transfer process perceptions in mathematical formula and, so, to quantify the single flow processes as well as to inversely verify and improve the process perception. The rather simple approach was chosen as addition to the widely used rainfall-runoffmodels that simulate the single runoff generation processes continuously in a spatially distributed way and fulfil the principle of mass conservation. The advantages of our approach are the high transparency, the use of only one calibration parameter (and therefore no interaction or intercorrelation of parameters) as well as the very little effort to set up and run the model. In addition, we distinguish all relevant runoff generation processes in our catchment.

In our model approach, deliberately interception and evapotranspiration have not been taken into account. The reason for this is on the one hand that these processes reduce the water supply very slightly during single storm events. The uncertainty range of the model parameters is likely to comprise the decrease of water yield due to interception and evapotranspiration. On the other hand, the simulation of evapotranspiration processes and their interaction with soil moisture is extremely complex: data of air temperature, solar radiation and/or humidity as well as landuse and soil parameters are needed. Instead of performing long term calculations with an evaporation-soil moisture routine we decided to use the calibration parameter $c f$, that allows to calibrate the actual soil moisture state.

Concerning the effect of afforestation, it might be that, due to higher infiltration rates in forest soils, the lower hillslopes saturate faster during longer rainfall. This corresponds with a higher value of $c f$. Consequently, the subsurface flow rate might increase. However, the over all water supply might be lower due to a higher interception and transpiration.

\subsection{Uncertainty of Parameters}

The uncertainty of the geometric parameters such as channel length, road area (Table 1) is very low. But the uncertainty of the subsurface flow parameters such as hydraulic conductivity is high. The parameters of pipeflow $P$ feature the highest uncertainty because mean flow rates of the macropore system are difficult to assess. Furthermore, the convergence of the subsurface flow in the thalwegs (parameters $h s$ and $c f$ ) strongly controls $P$ and $M$ but can only be calculated by calibration of $c f$. In the model, an increase of $h s$ stands for both the enlargement of the cross sectional area that is saturated along the channel edge and the increase of the hydraulic head (Eq. 6 to 8). Consequently, the higher $h s$, the higher matrixflow $M$ and pipeflow $P$.

Generally, one could calibrate further parameters besides $c f$ or use different parameter sets to get better or similar results. But to get the best fitting hydrograph was not our main objective. In contrast, we developed and used the model to proof and improve our process perceptions. One precondition was to use nearly exclusively measurable parameters.

\subsection{Comparison with a Similar Study}

Similar investigations at a delimited channel reach have been performed by [5] in a steep forested micro-scale basin of similar geological features in Japan. For an event of 48 $\mathrm{mm}$ total precipitation, a maximum 30 min-intensity of 5.2 $\mathrm{mm}$ and very wet antecedent conditions [5] showed by hydrometric evidence at an excavated pit that the matrix flow rate clearly exceeded the preferential flow rate. This can be seen as partly non consistent with our model results (Fig. 5). But as explained above our assessment of $M$ and especially $P$ is very uncertain. [5] stated that according to estimates of mean flow velocities the lower 1.8 to $8.8 \mathrm{~m}$ of a hillslope contribute subsurface flow during storms.

\subsection{Transferibility of Model Results}

The simulated runoff processes are likely similar in other low mountain range basins with similar climate, deep soils and similar proportion of impermeable areas. Here, in winter and spring mainly the fast subsurface flow generates the peak flow during floods of medium magnitude. In contrast, during the summer storms with high rainfall intensity the subsurface flow hardly contributes to the peak flow.

Our results are not necessarily valid for very intense and high summer storm. During these situations infiltrationexcess overland flow might occur large-scale on pastureland. As [17] showed by field evidence, the dense felt of grass roots can decrease the infiltration rate tremendously especially in spring when the grass is compacted. However, since this process did apparently not occur during the above shown events the parameters of the saturation overland flow respectively the corresponding runoff lines has been chosen as listed in Table $\mathbf{1 .}$

\subsection{Application of the Model to other Study Sites}

Generally, the model can easily be applied to other channel reaches whereas field surveys should be carried out to get information on the possibly occurring runoff processes and to determine the model parameters (Table 1). The latter have to be determined specifically for the respective channel. Basically, time series of precipitation and runoff as well as geometric data (channel length, channel width, area an location of impermeable areas) are needed. In our case, the model uses measurements of spring discharge as input, which clearly reduced model uncertainty. Hydrograph analysis are needed to determine the recession coefficient $k$ as well as the lag time $l t$. An analysis of soil physical properties help to determine the mean hydraulic conductivity $k f$ of the channel edge. In case that soil moisture measurements and piezometer data are available for the lower hillslope, one could use these data to determine the height of the saturated zone $h s$. Then, the calibration of $c f$ is theoretically no longer necessary.

\section{CONCLUSION}

This case study allowed for the quantitative assessment of the contribution of different stormflow sources by using a simple conceptual model that balances the different flows into a channel reach. Apart from one parameter (convergence factor $c f$ that controls the height of the saturated zone at the channel edge), the algorithms are based on measurable geometric and soil physical parameters. This balancing approach has been applied to three stormflow events of medium magnitude occurring at different moisture states. The results prove that the fast subsurface flow is clearly dominating dur- 
ing stormflow in winter and spring whereas the contribution of fast surface flow processes is very little. In contrast, during the summer storm the subsurface flow hardly contributes to the peak flow.

The parameter $c f$ has been found as very sensitive concerning the subsurface flow rate. Inversely, one can conclude that the extension of the contributing subsurface space in both lateral and vertical direction is the first order control on subsurface stormflow generation. The parameter $c f$ can be seen as representative for the actual moisture state of the basin. In this study $c f$ had to be calibrated event specifically. In future, it might be derived from antecedent precipitation indices and the actual season or in well equipped basins from soil moisture measurements.

During the wet spring period, the extension of the subsurface contributing area is likely widest and the susceptibility to floods is generally highest at this time. However, the specific subsurface stormflow generating processes (e.g. pressure propagation, preferential flow above an aquiclude etc.) are not yet understood and have to be investigated in further studies.

The observations and model results shown in this article are not necessarily valid for extreme precipitation. For instance, if a very intense and high rain event occurs in summer the surface flow rates might be much higher than assumed in this study. These topics will be the question of further research in the Frankelbach basin.

\section{CONFLICT OF INTEREST}

The authors confirm that this article content has no conflicts of interest.

\section{ACKNOWLEDGEMENTS}

This study has received European Regional Development funding by INTERREG III B NEW (WaReLa) and INTERREG IVB NWE (ForeStClim, www.forestclim.eu). The authors wish to thank the State office of geology and mining (LGB) Rhineland-Palatinate for providing basic data. We are grateful to the Forest Service Rhineland-Palatinate for the provision of the forest test sites and also to the tutors and students of the University Trier, who supported these investigations during field studies and laboratory work.

\section{REFERENCES}

[1] Anderson MG, Burt TP. Subsurface runoff. In: Anderson MG, Burt TP, Eds. Process studies in hillslope hydrology. Chichester: John Wiley and Sons 1990; pp. 365-400.

[2] Weiler M, McDonnell JJ, Tromp-Van-Meerveld I, Uchida T. Subsurface Stormflow. Encyclopedia of Hydrological Sciences; NYSE: Wiley, 2005.

[3] Mosley MP. Subsurface flow velocities through selected forest soils, South Island, New Zealand. J Hydrol 1982; 55: 65-92.

[4] Germann, PF. Rapid drainage response to precipitation. Hydrol Process 1986; 1: 1-13.

[5] Sidle RC, Tsuboyama Y, Noguchi S, Hosoda I, Fujieda M, Shimizu T. Stormflow generation in steep forested headwaters: a linked hydrogeomorphic paradigm. Hydrol Process 2000; 14: 69-385.

[6] Sklash MG, Stewart MK, Pearce AJ. Storm Runoff Generation in Humid Headwater Catchments - 2. A Case Study of Hillslope and Low-Order Stream Response. Water Resour Res 1986; 22(8): 7382.
[7] McDonnell JJ. A rationale for old water discharge through macropores in a steep, humid catchment. Water Resour Res 1990; 26(11): 2821-32.

[8] Rice KC, Hornberger GM. Comparison of hydrochemical tracers to estimate source contributions to peak flow in a small, forested, headwater catchment. Water Resour Res 1998; 34(7): 1755-66.

[9] Uhlenbrook S, Leibundgut C, Maloszewski P. Natural tracers for investigating residence times, runoff components and validation of a rainfall-runoff model. In: Dassargues A, Ed. Tracers and Modelling in Hydrogeology 2000; IAHS-Publ. No. 262, 465-472.

[10] Casper C, Volkmann, HN, Waldenmeyer G. The separation of flow pathways in a sandstone catchment of the Northern Black Forest using DOC and a nested Approach. Phys Chem Earth 2003; 28/ 67:269-75.

[11] Wenninger J, Uhlenbrook S, Tilch N, Leibundgut C. Experimental evidence of fast groundwater responses in a hillslope/floodplain area in the Black Forest Mountains, Germany. Hydrol Process 2004; 18: 3305-22.

[12] Anderson MG, Burt TP. The role of topography in controlling troughflow generation. Earth Surf Process 1978; 3: 331-44.

[13] Uchida T, Asano Y, Mizuyama T. Role of upslope soil pore pressure on lateral subsurface storm flow dynamics. Water Resour Res 2004; 40: 13.

[14] Tromp-Van-Meerveld HJ, McDonnell JJ. Threshold relations in subsurface stormflow: 1. A 147-storm analysis of the Panola hillslope. Water Resour Res 2006; 42(W02410): 1-11.

[15] Casper M, Gemmar P, Gronz O, Johst M, Stüber M. Fuzzy-logic based rainfall runoff modelling by using soil moisture measurements as representations for system state. Hydrol Sci J 2007; 52, 478-90.

[16] Scherrer S, Naef F, Faeh A, Cordery I. Formation of runoff at the hillslope scale during intense precipitation. Hydrol Earth Syst Sci 2007; 11: 907-22.

[17] Schobel S. Infiltrations- und Bodenabflussprozesse in Abhängigkeit von Landnutzung und Substrat in der Trier-Bitburger Mulde. Dissertation. University Trier 2008; p. 128.

[18] Hümann M, Schüler G, Müller C, Schneider R, Johst M, Caspari T. Identification of runoff processes - The impact of different forest types and soil properties on runoff formation and floods. J Hydrol 2011; 409: 637-49.

[19] Kirnbauer R, Haas P, Chifflard P. Hochwasserentstehung in der nördlichen Grauwackenzone. Beobachtung - Messung - Modellierung. TU Wien: Wiener Mitteilungen 2009.

[20] Hewlett JD, Hibbert, AR. Factors affecting the response of small watersheds to precipitation in humid areas. Paper presented at the International Symposium on Forest Hydrology. Oxford UK: Pergamon, 1967.

[21] Kienzler PM, Naef F. Subsurface storm flow formation at different hillslopes and implications for the 'old water paradox'. Hydrol Process 2008; 22: 104-16.

[22] Van Schaik L. The role of macropore flow from PLOT to catchment scale. Netherlands Geographical Studies Faculteit Geowetenschappen Universiteit Utrecht 2010.

[23] Garvelmann J, Külls C, Weiler M. A porewater-based stable isotope approach for the investigation of subsurface hydrological processes. Hydrol Earth Syst Sci 2012; 16: 631-40.

[24] Weiler M, McDonnell JJ. Conceptualizing lateral preferential flow and flow networks and simulating the effects on gauged and ungauged hillslopes. Water Resour Res 2007; 43: 1-13.

[25] Zehe E, Sivapalan M. Threshold behaviour in hydrological systems as (human) geo-ecosystems: manifestations, controls, implications, Hydrol Earth Syst Sci 2009; 13: 1273-97.

[26] McDonnell JJ, Sivapalan M, Vaché K. Moving beyond heterogeneity and process complexity: A new vision for watershed hydrology. Water Resour Res 2007; 43: 1-6.

[27] Johst M. Experimentelle und modellgestützte Untersuchungen zur Hochwasserentstehung im Nordpfälzer Bergland unter Verwendung eines neuartigen Spatial-TDR-Bodenfeuchtemessgeräts. Dissertation. University Trier 2011; Available at: http://ubt.opus.hbz-nrw.de/volltexte/2011/651/209 pp.

[28] Burt TP. Storm runoff Generation in Small Catchments in Relation to the Flood Response of Large Basins. In: Beven K, Carling P, Eds, Floods - Hydrological. Sedimentological and Geomorphological Implications. NYSE: John Wiley \& Sons Ltd. 1989; pp 11-35. 
[29] Beven K, Germann P. Macropores and Water Flow in Soils. Water Resour Res 1982; 18(5): 1311-25.

[30] Lehmann P, Hinz C, McGrath G, Tromp-Van-Meerveld HJ., McDonnell JJ. Rainfall threshold for hillslope outflow: an emer- gent property of flow pathway connectivity. Hydrol Earth Syst Sci 2007; 11: 1047-63.

Received: March 22, 2013

Revised: June 06, 2013

Accepted: June 24, 2013

(C) Johst et al.; Licensee Bentham Open.

This is an open access article licensed under the terms of the Creative Commons Attribution Non-Commercial License (http://creativecommons.org/licenses/by-nc/3.0/) which permits unrestricted, non-commercial use, distribution and reproduction in any medium, provided the work is properly cited. 